\title{
Equalorial
}

\section{A rotina extraordinária da comunidade de Paracatu de Baixo (MG) após o rompimento da barragem de Fundão*}

Gabriela de Paula Marcurio

Mestranda em Antropologia Social - Universidade Federal

de São Carlos (UFSCar)

\section{RESUMO}

Descrevo a rotina da comunidade de Paracatu de Baixo, no município mineiro de Mariana, atingida pelo rompimento da barragem de rejeitos de Fundão, da mineradora Samarco (Vale e BHP). Os moradores foram deslocados compulsoriamente da zona rural para a sede municipal, sem a possibilidade de desempenhar seus modos de vida. Argumento que o cotidiano não foi restabelecido após o desastre, visto que a rotina é marcada pelo extraordinário. A partir da pesquisa de campo, analiso a categoria "atingido" e as reuniões com técnicos de uma assessoria e com representantes da mineradora. Evidencio como essas atividades controlam o tempo dos moradores e como eles criam estratégias para lidar com o tempo dissociado da terra natal.

Palavras-chave: Comunidade; Tempo; Reunião; Desastre; Minas Gerais.

\footnotetext{
* (N.E.) O presente artigo é uma versão modificada da primeira publicação. Por motivos éticos e concernentes à segurança dos(as) interlocutores(as), fez-se alteração de alguns nomes e trechos, conforme solicitado pela autora.
} 


\title{
The extraordinary routine of the community of Paracatu de Baixo (MG/Brazil) after the disruption of Fundão dam
}

\begin{abstract}
I describe the routine of the Paracatu de Baixo community in Mariana town, in the state of Minas Gerais, Brazil, affeceted by the break of Fundão's tailings dam, owned by mining company Samarco (Vale and BHP). Residents were forced to move from the countryside to a municipal headquarters without the possibility to keep their own lifestyle. My argument is that daily life was not restored after the disaster, and the routine is marked by the extraordinary. From the field research, I analyze the "affected" category and the meetings with technicians from an advisory and with representatives of the mining company. I show how these activities control the time of residents and how they create strategies to deal with the time dissociated from their homeland.
\end{abstract}

Keywords: Community; Time; Meeting; Disaster; Minas Gerais.

\section{La extraordinaria rutina de la comunidad de Paracatu de Baixo (MG/Brasil) tras la ruptura de la presa Fundão}

\section{RESUMEN}

Describo la rutina de la comunidad de Paracatu de Baixo en Mariana, Minas Gerais, Brasil, que fue afectada por la presa de relaves de Fundão, propiedad de la empresa minera Samarco (Vale y BHP). Los residentes fueron desplazados obligatoriamente del campo a la ciudad, sin la posibilidad de realizar sus formas de vida. Sostengo que la vida cotidiana no se restableció después del desastre, ya que la rutina está marcada por lo extraordinario. Con base en la investigación de campo, analizo la categoría "afectado" y las reuniones con técnicos de un asesoramiento y con los representantes de la compañía minera. Muestro cómo estas actividades controlan el tiempo de los residentes y cómo crean estrategias para lidiar con el tiempo disociado de su tierra natal.

Palabras clave: Comunidad; Tiempo; Reunión; Desastre; Minas Gerais. 


\section{Introdução ${ }^{1}$}

O tema que pretendo analisar neste artigo é a rotina da comunidade ${ }^{2}$ de Paracatu de Baixo, de aproximadamente trezentos habitantes, localizada no distrito de Monsenhor Horta, no município de Mariana, Minas Gerais. A maioria dos moradores foi deslocada compulsoriamente para a sede municipal, devido à destruição da terra em que vivia pelos rejeitos minerais decorrentes do rompimento da barragem de Fundão, em 05 de novembro de 2015, propriedade da mineradora Samarco S.A., pertencente às multinacionais Vale S.A. e BHP Billiton Ltda. Esses moradores foram espalhados pela zona urbana em diferentes bairros, em casas alugadas pela Fundação Renova, organização fundada a partir do Termo de Transação e Ajustamento de Conduta (TTAC) das mineradoras com o Ministério Público Federal e Estadual de Minas Gerais e do Espírito Santo. A Renova tem o objetivo de "reparar os danos" do maior desastre socioambiental do país, responsável por despejar cerca de 60 milhões de metros cúbicos de rejeitos minerais, que percorreram 663 quilômetros de Mariana (MG) a Linhares (ES).

O meu argumento central é de que o cotidiano dos moradores foi totalmente alterado e não se restabeleceu, desde que as práticas que organizavam a vida social não foram retomadas, em especial, o trabalho na roça voltado para a subsistência, cultivando principalmente milho, feijão e mandioca. Assim, relaciono o tempo e a terra como fundamentos para os modos de vida da comunidade. Fora do território que habitavam, seus modos de vida foram impedidos, tendo efeitos diretos para a forma de contar, organizar e sentir o tempo, conforme os relatos que ouvi dos moradores.

Começo descrevendo a rotina “em Mariana”, expressão usada pelos moradores para distinguir a sede municipal em relação às comunidades rurais. Os dias são organizados pela Comissão de Atingidos pela Barragem de Fundão (CABF), com o auxílio técnico da Cáritas Brasileira - Regional Minas Gerais, instituição escolhida pelo Ministério Público para assessorar a CABF no município. O tempo é marcado pelas reuniões entre os moradores e os técnicos da Cáritas e da Fundação Renova. Essa organização é baseada na incerteza e no sofrimento, pois, "depois que a lama passou, tudo mudou”, como concluiu uma moradora de Paracatu de Baixo. Nesse sentido, o tempo também mudou: ou "não tem tempo para nada", ou "o tempo passa devagar".

Em seguida, mostro que os moradores precisaram "aprender a ser atingido". O termo atingido foi reivindicado seguindo as mobilizações do Movimento dos Atingidos por 
Barragens (MAB), num processo de reconhecimento em oposição à definição de "impactado", utilizada pelas mineradoras. Os moradores explicam que a noção de atingido evidencia o desastre no tempo, indicando sua dimensão prolongada, ao passo que "impactado" delimita um "acidente" localizado e finito, administrado pelas mineradoras nos termos patrimoniais de perdas e danos. Neste texto, privilegio a grafia atingida, pois foi com elas que mais conversei e que, portanto, desenvolvi a maior parte da pesquisa.

As reuniões são centrais para a passagem seguinte de meu argumento, porque, inicialmente, elas foram apresentadas como único meio de socialidade da comunidade. Em contrapartida, são nesses encontros em que as estratégias das (os) atingidas (os) são vistas, uma delas é o método para conter o tempo administrado pelas empresas. As reuniões consistem em diversos tipos de encontros, por exemplo, com a assessoria técnica, a Fundação Renova, o Ministério Público, advogados, pesquisadores e jornalistas. Além disso, pode-se referir também a assembleias, eventos, entrevistas e seminários.

Para analisar as situações que presenciei utilizo duas figuras de linguagem: a rotina extraordinária, oximoro que representa a vida depois do deslocamento compulsório; e o cotidiano ordinário, pleonasmo que enfatiza os modos de vida em Paracatu de Baixo. As atingidas e os atingidos diferenciam os tempos antes e depois do rompimento da barragem. Em suas falas comparam as condições de vida, as práticas e as atividades, positivando o passado na comunidade, onde a vida era "livre" e "solta", em contraste com a vida na cidade.

Por fim, gostaria de fazer duas orientações para guiar a leitura deste artigo: a primeira relativa à terminologia, a segunda relativa à pesquisa de campo. Primeiramente, ressalto que o termo comunidade é usado de maneira polissêmica pelos moradores, fazendo referência ao povo, à terra natal ou aos modos de vida lá estabelecidos. Por isso, em alguns trechos essa noção aparece conjugada no passado e, em outros, conjugada no presente, mostrando as variações semânticas utilizadas, por exemplo: "a comunidade acabou" e "a comunidade quer". Essas variações põem luz ao meu problema central do tempo para a comunidade. Assim, insisto nessa noção desde o início deste texto, afirmando que analiso a rotina da comunidade, mesmo não se tratando da organização espacial original na zona rural.

Segundo, gostaria de advertir a respeito de minhas condições de pesquisa, evidentes ao longo deste texto. A pesquisa de campo de cinquenta dias, entre outubro de 2018 e fevereiro de 2019, foi cercada por dificuldades em acompanhar os moradores. Essas situações fizeram com que minha atenção se voltasse para dois fenômenos: a) o fechamento da comunidade em si mesma, evitando o contato com pesquisadores e jornalistas; b) a sobreposição dos assuntos referentes ao embate direto com as mineradoras 
em relação aos temas cotidianos da comunidade, a exemplo da ocasião que presenciei no evento de três anos do rompimento da barragem, responsável por cancelar os rituais do Dia de Finados, organizados pelos moradores no cemitério de Paracatu de Baixo. Esses fenômenos alteraram minha pesquisa e fundamentaram meu argumento central.

O texto segue esse percurso em três partes: na primeira parte trabalho com os relatos dos moradores a respeito da vida depois do desastre, no processo em que eles se tornaram atingidos; na segunda parte me dedico a descrever as atividades que presenciei, especificamente, as reuniões; na terceira parte analiso a rotina extraordinária e mostro uma estratégia que os moradores criaram para lidar com o tempo, a metodologia de "ir aos poucos". Por fim, faço algumas considerações finais acerca dos movimentos das atingidas e dos atingidos para viver após o "fim do nosso mundo", como resumem os efeitos do rompimento da barragem.

\section{"Somos atingidos todos os dias"}

No dia 05 de novembro de 2015 a "lama" passou e arrastou consigo árvore, gente, carro, bicho e casa. Por onde ela passou alterou não só a terra, mas também o tempo. Na minha primeira visita a Paracatu de Baixo, no dia 12 de outubro de 2018, fui à celebração de Nossa Senhora Aparecida, ocorrida na Igreja de Santo Antônio, a única construção que não foi devastada pela "lama" na parte baixa da comunidade. Nessa ocasião conheci Mirella, Dayanne e sua sogra, Rosalina, ou melhor, Zaia, como os moradores a conhecem. Elas me explicaram como o tempo é e passa diferente "em Mariana", referindo-se especificamente à sede municipal. Para as crianças, os jovens e os idosos o tempo ficou lento, "sem nada para fazer", porque não acordam cedo e vão trabalhar nas lavouras, cuidando dos alimentos e dos animais; não podem ir à casa de um vizinho à tarde nem encontram os colegas na missa de domingo; as crianças não podem brincar "soltas" e andar sozinhas nas ruas, "ficam trancadas em casa".

Em contrapartida, o tempo para aqueles que participam ativamente da Comissão de Atingidos é definido pela sua escassez, marcado pelas reuniões. O tempo se estende até a madrugada: as reuniões não têm hora para acabar. As atingidas dizem que "não têm tempo" para as atividades pessoais, para descansar, dormir e para o lazer, a ponto de precisarem "abrir mão do pessoal para o coletivo", deixar de lado todas as atividades e interesses individuais para lutar pelos direitos suprimidos pelo desastre. Todos os dias marcam uma nova forma de se relacionar em reuniões; em casa com um telefonema ou 
visita inesperada de um técnico, pesquisador ou advogado; ou ainda, com um novo desastre, como o rompimento da barragem de rejeitos em Brumadinho (MG), no dia 25 de janeiro de 2019.

Era minha primeira semana de pesquisa de campo no ano de 2019. Nesse dia, os sinos tocaram, não para marcar a hora, como se ouve da Igreja Nossa Senhora do Carmo, no centro da cidade. Lembrei-me que os sinos dobram pelos mortos e pelos santos e santas. Eram quase três da tarde e os sinos tocaram por cerca de dez minutos ininterruptos. Olhei para fora e não vi nada diferente. Desci as escadas, fui até a rua. Virei à esquina, segui a Rua Direita. Subi a ladeira até a Praça Minas Gerais. Tudo como de costume: algumas pessoas andavam pela rua, os comércios estavam abertos, todos trabalhando. Nenhuma aglomeração na praça em frente à Igreja. Sabia do que se tratava, ninguém precisava dizer, tinha visto as notícias. Descendo a ladeira, ao meu lado, um casal conversava: "Vão achar que é aqui de novo". Pois, foi assim, como pude testemunhar nos dias que se seguiram.

Todas as atividades programadas para as populações atingidas pela barragem de Fundão no município foram canceladas. A Unidade Básica de Saúde (UBS) Bento/Paracatu estendeu o horário de funcionamento e abriu no final de semana para atender as comunidades ${ }^{3}$. Ouvi muitos relatos de atingidas (os) de Mariana que passaram mal, "como se estivesse vivendo tudo de novo". Depois de duas semanas, ouvi um atingido dizer que seu filho não ia à escola porque estava com medo da "lama" chegar novamente. Os problemas de saúde foram agravados por causa do rompimento da barragem no Córrego do Feijão, também da mineradora Vale, a aproximadamente 130 quilômetros do município de Mariana. A "lama" não chegaria, mas os jornalistas e pesquisadores chegaram, mais uma vez.

Nesse contexto, enfrentei dificuldades para estabelecer relações com os moradores. Tentava marcar conversas e visitas, mas não se concretizavam, geralmente, "pela falta de tempo" das (os) atingidas (os). As conversas durante as reuniões eram rápidas, na maioria das vezes com as mulheres que conhecera em minhas primeiras visitas, em 2018. Essa relação fundada pelo desastre e continuada pelo silêncio se estendeu por todo o período de pesquisa, de modo que aproveitava os relatos em público e os convites oferecidos, investigando as informações que cada silenciamento transmitia. Aproximo-me, aqui, da análise acerca das dificuldades de pesquisa narradas por Jeanne Favret-Saada (2005, p. 160) com os camponeses de Bocage, na França, onde o silêncio acerca da feitiçaria não reduziu a importância dessa prática, negada em primeira mão. Desse modo, o tempo se constituiu 
como uma relação (GOLDMAN, 2005, p. 150), ampliando os encontros e possibilitando interpretações das linguagens não-verbais.

As circunstâncias em que a comunidade de Paracatu de Baixo se encontrava não permitia que eu insistisse em encontrar e conversar com os moradores fora das reuniões. A ameaça da presença dos pesquisadores e dos jornalistas intensificou-se após o rompimento da barragem. A comunidade se tornou um alvo não só das mineradoras, como de diferentes profissionais interessados em trabalhar com o desastre. $\mathrm{O}$ assédio e a falta de privacidade são descritos recorrentemente pelos moradores que reclamam do "cansaço" de "ser atingido", agravado pelos dispêndios de forças e de tempo sem receber seus resultados, pois, de acordo com o que me relataram, tanto as mineradoras, quanto os profissionais não retornam com os materiais, os planejamentos e as conclusões que produziram a partir das narrativas das (os) atingidas (os).

Nesse sentido, percebi o fechamento da comunidade em torno de seus membros: uma estratégia de preservação após o impedimento da organização da vida social própria de Paracatu de Baixo. Posteriormente, uma técnica explicou-me que, além de ser uma estratégia dos moradores, é uma diretriz seguida e orientada pela assessoria, em que todos são indicados a não conversar com pesquisadores, evitando os riscos da exposição e das ameaças. Nessas condições, os moradores tentam estabelecer minimamente as relações comunitárias, aproximando-se, quando possível, do cotidiano. No entanto, são importunados semanalmente por técnicos e novos profissionais.

Os técnicos consistem em advogados, engenheiros, arquitetos, psicólogos e cientistas sociais contratados pela Renova e pela Cáritas para trabalhar com as (os) atingidas (os) em campos opostos: os primeiros são contratados pela Fundação financiada pelas mineradoras para administrar e "reparar os danos" do maior desastre socioambiental do país (cf. MILANEZ e LOSEKANN, 2016); os segundos para auxiliar os moradores no processo de reivindicação dos direitos violados. Nesse sentido, a assessoria técnica é um marco importante de conquista das comunidades de Mariana junto ao Ministério Público de Minas Gerais.

As formas de vida depois do rompimento da barragem são explicadas pelos moradores a partir da expressão "somos atingidos todos os dias", compilando diversas formulações, das quais listo algumas a seguir. "Ser atingido todos os dias" é: viver de forma temporária, numa casa alugada pela Renova; não trabalhar na agricultura e na pecuária familiar ou para os "sitiantes", nas monocultoras de café; é, ainda, não ter acesso ao rio Gualaxo do Norte; não ter contato com parentes que moravam na mesma casa ou em 
casas ao lado, em extensões de um mesmo terreno; nem a relação com vizinhos e amigos, com visitas constantes e auxílios nas atividades diárias, como na criação dos filhos, "soltos" e "livres". É, enfim, não ter a missa, a Folia de Reis e as festas católicas como antigamente; é sofrer discriminação das pessoas que não foram atingidas e esconder a própria condição por ser criminalizada pelas mineradoras; é ter que participar de treinamentos do "plano de evacuação" no território devastado somente após o desastre; é, por fim, sofrer com os problemas de saúde que acometem e ameaçam a todos, sem contar o risco de contaminações futuras com a "lama tóxica".

Há quase cinco anos, a comunidade tem sua rotina organizada em função do rompimento da barragem. Uma moradora disse que as empresas mineradoras "fazem o problema dos atingidos render", pois suas respostas vêm muito devagar, as negociações "tão indo, mas não voltam". Ao passo que os moradores estão "sendo atingidos todo dia", sofrendo com os deslocamentos e rompimentos. A população se descreve como "exausta" e "cansada". O desgaste, o cansaço e a desesperança aumentam com o tempo, bem como a descrença na "luta" e nas chances de "vencer" os processos jurídicos. O desânimo causado pelas diversas reuniões, embates judiciais e discussões sem resultados abatem e afastam os membros da comunidade.

Viver como atingida (o) é viver de forma temporária, entre o medo e a incerteza. Segundo o levantamento feito por Victoria Sword-Daniels et al. (2016) a respeito do contexto norte-americano, a incerteza é incorporada pelas vítimas de grandes desastres, a ponto de não ser possível fazer planos para o futuro. No mesmo sentido, os relatos que ouvi sugerem que a vida permanece no desastre, em torno dele. A dor se estende no tempo como condição compartilhada de toda a comunidade, como analisou Andréa Zhouri (2018, p. 11) acerca dos atingidos em Mariana, relacionando o sofrimento social à "aniquilação de modos de ser, fazer e viver territorializados".

A relação entre os desastres e o tempo é um tema crescente na literatura antropológica. Delimito minha análise a uma perspectiva das pesquisas recentes, partindo dos trabalhos de Veena Das (1995). Dessa maneira, o rompimento da barragem de Fundão pode ser definido como um "evento crítico", termo de Das (1995, p. 5) para se referir a diversas situações de extrema violência na Índia, cujo um dos efeitos é a alteração do tempo para as suas vítimas. A variedade de formas de compreender o tempo está em contraste e em conflito com a forma unitária proposta pelo Estado-nação. O caso que a autora (Ibid., p. 137-174) utiliza que mais se assemelha ao que analiso é o vazamento de metil isocianato em Bhopal, nos anos 1980. 
Em outra perspectiva, mas ainda em uma abordagem social dos desastres, a análise de Anthony Oliver-Smith (1999, p. 193) relaciona esses acontecimentos às desigualdades socioeconômicas, afirmando que as catástrofes atingem com mais severidade populações pobres e vulneráveis, provocando uma descontinuidade no espaço e no tempo. No mesmo sentido, Juan Calis et al. (2017, p. 14-15) entendem que os desastres ultrapassam os "tempos concretos", mesmo podendo situá-los com um marco temporal específico, eles afetam o futuro e a vida das populações de forma sucessiva. Em consonância, Renzo Taddei (2015, p. 316) argumenta que um "desastre não é um fato isolado, mas um processo com desenrolar temporal extenso", evidenciando a vulnerabilidade e o risco antes e depois de uma tragédia.

A partir dessas premissas teóricas construo meu argumento de que o sofrimento de "ser atingido todos os dias" constitui a rotina extraordinária, cujo tempo não é determinado pelos moradores. O cotidiano ordinário, anterior ao rompimento da barragem, é mencionado constantemente por atingidas (os), inicialmente com a formulação "Em Paracatu era assim...", em contraste com a forma de vida na cidade. Um exemplo recorrente é a alimentação, já que a comida vinha da horta e da roça dos próprios terrenos, de modo que os moradores não precisavam pagar por esses alimentos nem se locomover até a feira, como ocorre "em Mariana".

A relação com a terra organizava o tempo. Os ciclos agrícolas e do rio Gualaxo do Norte classificavam as atividades diárias. Essas relações são semelhantes em diversos contextos etnográficos na zona rural brasileira, conforme a distinção do tempo feita inicialmente por Moacir Palmeira (2013 [1971], p. 343) acerca do "tempo antigo" relativo à vida no engenho de açúcar, em oposição às usinas na Zona da Mata pernambucana. Essa categorização foi identificada também por Ellen Woortmann (1991) e John Dawsey (1997), ao aproximarem o "tempo antigo" ao "tempo de fartura" em contraste com o "tempo do dinheiro", referente a comunidades litorâneas no Nordeste e a boias-frias no estado de São Paulo, respectivamente.

As atingidas e os atingidos afirmam que não é possível recuperar as formas de vida como eram no passado. O que se perdeu e a condição que se estende sendo atingido por mais de quatro anos não podem ser restituídos por indenizações ou pelo reassentamento. Rosária, moradora de Paracatu de Baixo, explicou no seminário "Mariana 3 anos depois", em 03 de novembro de 2018: "O agricultor tem amor pela terra. Eles [as mineradoras] não amam a terra como os agricultores amam, eles amam o ouro. Agricultor ama a terra. A terra é o tamanho da vida da gente, é o preço de nossa vida". Ela continuou comparando 
as formas de vida antes e depois: "não somos independentes. [...] Não tem como medir nosso sofrimento. Me dói não comer a comida que eu planto [...]. Quero que a terra valha o amor que tenho por ela".

Os embates das (os) atingidas (os) frente às mineradoras evidenciam dois modos de pensar e de agir muito diferentes. De um lado, a lógica do amor, do cuidado com a terra e do território sem fronteiras fixas entre as comunidades rurais. De outro lado, a lógica do dinheiro, da propriedade e da destruição, que desloca e despersonaliza a natureza, como avaliou Ailton Krenak (2019) após a destruição de sua comunidade à margem do Rio Doce. Esses confrontos ficam evidentes durante as reuniões, onde atingidos e técnicos se enfrentam, como mostrarei a seguir.

\section{"Parece que eles vivem para isso, para as reuniões"}

O portão da sede da Comissão de Atingidos pela Barragem de estava fechado. A porta estava aberta, de modo que eu podia ver duas secretárias. Lembrava da sala com duas mesas, agora havia três. Era a primeira reunião que eu fui convidada a participar, em 24 de janeiro de 2019. A terceira secretária apareceu e me guiou para a reunião da Comissão de Paracatu com a assessoria técnica da Cáritas. Havia sete moradores sentados em um semicírculo na sala de reuniões e dois técnicos em pé, na frente da sala. Sentei-me ao fundo, atrás de Maria Geralda, moradora que conhecera na celebração de Nossa Senhora Aparecida, no ano anterior. Cumprimentei-a e conversamos rapidamente. A técnica começou sua fala com mensagens de boas-vindas e seguiu com explicações a respeito das "rodas de conversa" propostas pela Fundação Renova para a semana seguinte. O intuito era se prepararem para as decisões e os prazos estipulados pela empresa.

Em meio a discussão, uma moradora questionou: "Por que a gente vai chutar, se estamos caminhando esse tempo todo?!". Era um convite a seus vizinhos para discutirem as propostas em conjunto, antes de tomarem as decisões rapidamente, ou seja, "chutar". Uma proposta para que todos conversassem com calma, a despeito do tempo estipulado pela Renova, mesmo diante da insistência das mineradoras e das ameaças de atraso nas obras do reassentamento. As decisões acerca da pavimentação das ruas, do sistema de água, da arquitetura da praça e da igreja deveriam ser tomadas pela comunidade, antes que "eles fechem" e não seja possível "voltar atrás", como concluiu, em seguida, outro morador em referência aos técnicos da Renova que coordenam os projetos. 
Os técnicos escreviam em um quadro branco e abriam mapas com o projeto da área do reassentamento. Levantei-me para analisar o mapa com os moradores. Eles apontavam para os retângulos que delimitavam seus terrenos e de seus familiares. Quase toda a área era ocupada, sendo que grande parte estava reservada para a Área de Proteção Permanente (APP). Os moradores pensaram em maneiras de escolher a pavimentação das ruas. Depois, falaram das estratégias da Fundação Renova para limitar suas decisões, impondo projetos e prazos, transferindo a culpa aos moradores pelo atraso das obras, incitando que as deliberações fossem rápidas para que a construção das casas começasse logo.

Não consegui interagir diretamente com os moradores, com exceção de Maria Geralda. Aproximei-me dos grupos, tentando acompanhar as conversas, mas logo se dissipavam. Esse modo de interação foi uma constante em todas as reuniões: grupos de amigos se formavam; eu tentava acompanhar a conversa, mas rapidamente todos iam embora. Eu, geralmente, falava com pessoas que já conhecia, continuando os assuntos tratados pelos técnicos.

Logo que cheguei em Mariana, em janeiro de 2019, uma moradora me enviou as agendas semanais de atividades das (os) atingidas (os). As comunidades seguem duas programações, uma elaborada pela Fundação Renova e outra pela Comissão de Atingidos em conjunto com a Cáritas. As agendas são disponibilizadas nas segundas-feiras em grupos em aplicativos de celular. Luzia, membro da Comissão de Paracatu, explicou-me que existem dois tipos de reuniões: as reuniões das (os) atingidas (os) com os técnicos da Renova e da Cáritas; e, as reuniões dos moradores. Depois de duas semanas em que eu tentava acompanhá-las, Luzia avisou que eu poderia ir em todas as reuniões. Entre 24 de janeiro e 26 de fevereiro de 2019 fui em três reuniões organizadas pela Cáritas; três reuniões com as comunidades de Paracatu de Baixo e Bento Rodrigues; cinco reuniões organizadas pela Renova; e, uma assembleia com a presença do Ministério Público. No total, foram doze reuniões em trinta e quatro dias, número baixo levando em conta que este foi um mês atípico, pois todas as atividades foram canceladas do dia 26 de janeiro ao dia 02 de fevereiro, devido ao rompimento da barragem em Brumadinho.

As reuniões marcam o tempo das (os) atingidas (os), sendo um dos elementos do que chamo de rotina extraordinária. Maria Geralda me contou que "no início" havia reuniões mais de uma vez por dia e outras que duravam o dia todo, geralmente quando envolviam julgamentos no Fórum Municipal, onde as (os) atingidas (os) esperavam o dia todo, "sem ter o que comer". Presenciei essa situação em minha primeira viagem para pesquisa de campo, em 05 de outubro de 2017: as (os) atingidas (os) estavam na calçada, na frente do 
Fórum, e os "homens de terno e carrão", advogados das mineradoras, chegavam juntos, saíam e paravam a audiência quando queriam, para "intimidar", como avaliaram os moradores ao meu lado.

Os moradores das comunidades atingidas precisaram formar Comissões para organizar as atividades, os processos jurídicos e a maneira de se relacionar com as mineradoras. As Comissões são compostas, em cada comunidade, por moradores eleitos pela maioria em votação. As reuniões são divididas por comunidade, com exceção das assembleias e do "GTzão", Grupo de Trabalho com todas (os) atingidas (os). Há um conjunto de atividades que são fixas, como os GTs de Paracatu de Baixo com a Cáritas, organizados para discutir questões próprias do interesse da comunidade, reuniões voltadas para a "base" e a "formação", como me explicou um técnico da assessoria. Já as reuniões marcadas pela Renova são para tomada de decisão ou exposição do andamento dos processos de "reparação" e "compensação".

Essas atividades ocorrem, na maioria das vezes, no escritório da Comissão de Atingidos, uma casa alugada pela Fundação Renova. Há três salas para reuniões, mas todas as atividades que presenciei aconteceram na maior sala, com aproximadamente trinta cadeiras enfileiradas em dois conjuntos, com uma passagem no meio dando acesso à cozinha. Esses encontros são organizados pela Cáritas ou pela Renova. Em cada ocasião, os técnicos responsáveis ficam em pé, na frente da sala, ao lado do quadro branco. Além disso, há reuniões com famílias separadamente para falar do cadastro das (os) atingidas (os), do reassentamento e das indenizações, que podem ocorrem em suas próprias casas ou nas sedes das organizações. A sede principal da Renova é a Casa do Jardim, um casarão no centro histórico de Mariana. Há uma pequena sala de reunião no segundo andar. $\mathrm{O}$ primeiro pavimento é um espaço aberto ao público, semelhante a um museu, com guias que informam a respeito da cidade e explicam os painéis referentes ao rompimento da barragem de Fundão e aos projetos de reassentamento.

As reuniões seguem uma mesma ordem: primeiro a fala dos técnicos, trazendo informações e indagando as (os) atingidas (os) a respeito do tema proposto; os moradores respondem e conversam entre si; os técnicos anotam e finalizam a reunião. A Cáritas faz reunião para antecipar ou explicar os assuntos tratados pela Renova, como o encontro que comentei no início desta seção, no dia 24 de janeiro, antecipando os temas que foram apresentados pela Renova nos dias 5, 6 e 7 de fevereiro. As reuniões dos dias 12 e 19 do mesmo mês foram, respectivamente, para avaliar as reuniões anteriores e para mostrar os resultados obtidos. 
Em todas as reuniões que participei circulavam três listas de presença diferentes, uma da CABF, uma da Cáritas e outra da Renova. Uma secretária da Comissão gravava tudo e fazia uma ata. Os técnicos da Cáritas e da Renova anotavam em cadernos os acontecimentos, para a produção posterior de atas. Essa combinação de reunião, registro e documento ilustra o argumento de Hannah Brown et al. (2017, p. 23), de que a reunião cria um ciclo, fazendo registros e documentos, que, por sua vez, produzem reuniões, sucessivamente. Segundo Brown et al. (2017, p. 3), apesar desses encontros serem definidos de acordo com o contexto etnográfico, trata-se de uma forma organizacional reconhecida formalmente.

A reunião é composta, em seu conteúdo e em sua forma, por uma "linguagem" muito específica. Diversos moradores relataram como foi difícil aprender esse idioma. Maria das Dores, moradora de Paracatu de Baixo, contou-me que precisa interromper as falas para pedir aos técnicos que expliquem o que querem dizer, no meio das reuniões, contrariando o formato definido desse processo. Ela me explicou que aprendeu "observando", justificando que o fato de não ter escolaridade não a impede de saber "o que tá certo e o que tá errado". Dessa forma, as (os) atingidas (os) criaram estratégias para "aprender" essa "linguagem", a exemplo de Luzia, que anotava e me aconselhava a fazer o mesmo, sempre perguntando se eu tinha escrito algo, pois era importante. No entanto, a apropriação dessa "linguagem" não é suficiente para alcançar as mineradoras em sua eficiência técnica e seu controle do tempo, do espaço e dos processos, como argumentou Luzia: "eles fazem tudo em cima da hora, a gente tem que fazer tudo com seis meses de antecedência, senão não pode".

Para além das apropriações de técnicas das empresas e do Estado, as (os) atingidas (os) desenvolveram outros procedimentos. No geral, a maioria dos participantes fica em silêncio durante toda a reunião ou, ainda, conversa entre si acerca de diferentes temas, que não os mencionados pelos técnicos. A reunião do dia 12 de fevereiro é um exemplo: os moradores não respondiam às propostas feitas pelos técnicos da Renova, conversando e perguntando temas que lhes interessavam. Nesse dia, o encontro semanal do "GT de Paracatu de Baixo" tinha o objetivo de discutir os procedimentos das "rodas de conversa" da semana anterior, acompanhadas por poucos moradores. Os técnicos insistiam em uma análise feita pelas (os) atingidas (os) a respeito da conduta da Fundação Renova. Por outro lado, elas e eles falavam entre si e pediam informações acerca do que foi debatido e decidido da questão da água não tratada e da pavimentação no reassentamento. Nessa situação, um funcionário da Renova afirmou que não podiam resolver as questões, pois há o "problema do consenso", referindo-se à dificuldade que os técnicos têm em pensar 
a "forma de decisão futura": "vocês tão vendo como é difícil para Renova resolver isso. A gente está numa posição muito difícil", concluiu.

Estratégias como não aderir às propostas de uma reunião, conversar outros temas, andar pela sala, questionar a reunião em sua forma e organização, sua "linguagem" e seus objetivos são maneiras de agir que divergem da coerção e do consenso que esse modelo impõe. Os objetivos de uma reunião são criar resultados, como define Annelise Riles (2017). Há, no entanto, diferenças muito grandes entre os resultados esperados pela Renova, pela Cáritas e pela Comissão de Atingidos, considerando ainda a heterogeneidade que compõe as (os) atingidas (os). Retomando outro argumento de Brown et al. (2017, p. 8), as reuniões partem de uma multiplicidade com o objetivo de produzir o consenso, em uma unidade negociada. Nesse processo, as estratégias de silêncio e de não adesão às propostas não são registradas nas atas, aparecem codificadas na forma de consentimento, devido à falta de oposição declarada. Essa situação ficou evidente no dia 19 de fevereiro, quando os técnicos da Renova trouxeram os resultados das "rodas de conversa" sistematizados em quatro grandes tabelas. Um funcionário explicou que as formulou a partir das atas das reuniões, nas quais foram registrados os "pontos de consenso", indicando que "não houve oposição", de acordo com suas palavras. Esses resultados mostravam, por exemplo, a preferência dos moradores por pavimentação de asfalto em todas as ruas do reassentamento, porque não havia posicionamento contrário, ao passo que cerca de dez moradores afirmaram a preferência.

Os documentos simplificam e empobrecem as relações, mostrando resultados, mas apagando os processos, os debates e as negociações precedentes (RILES, 2017). As reuniões podem ser interpretadas, nesse sentido, como um espaço de embate e de conflito, de acordo com a proposta de John Comerford (2002; 2003) de avaliá-las como rituais na lógica da "sociabilidade agonística". Desse modo, os moradores das comunidades atingidas precisam lutar para reivindicar seus direitos contra as mineradoras criminosas. As reuniões incessantes com a Renova podem ser entendidas como negociações da pena das mineradoras e concessão dos direitos dos atingidos, que, diferentemente dos procedimentos jurídicos comuns, precisam provar a inocência.

Seguindo a corrente de Mariza Peirano (2002), partindo de Stanley Tambiah (1985), Comerford (2002, p. 159) pensa as reuniões como rituais performativos, produzindo uma "construção ritualizada de símbolos coletivos" (COMERFORD, 2002, p. 149). Nessa linha, as reuniões também são espaços de encontro, de conversa e de amizade entre os moradores. Em certa medida, trata-se do único ponto de encontro para as (os) atingidas 
(os): "parece que eles vivem para isso, para as reuniões", como confessou a mim uma técnica da Cáritas. Essa hipótese de que a comunidade se reduziu às reuniões aparece como efeito perverso do desastre, passando por cima das lutas que os moradores travam com esse modelo de encontro, consenso e "reparação" à destruição.

Pensar a reunião como um ritual tem implicações, considerando que esse encontro não é pensado dessa forma pelos moradores. Os rituais "persuadem” e as reuniões "não persuadem" como argumenta Thais Mantovanelli (2016), inspirada em Marilyn Strathern (2014), em sua tese a respeito das reuniões entre os "brancos" da Usina Hidrelétrica Belo Monte e os Xikrin do Bacajá. A reunião é símbolo de ineficácia e seus meios são específicos dos "brancos", em oposição aos rituais. Entendo que para as (os) atingidas (os) as reuniões são ineficazes em sua quantidade exagerada que não produz resultados, porque “a Renova não quer" resolver os problemas que as mineradoras causaram, as quais não querem "assumir" a culpa, como disseram meus interlocutores.

Muitos moradores deixaram de participar desses encontros alegando a "perda de tempo", como declarou Maria das Dores: "as reuniões falam da mesma coisa, só coisas repetidas. Cansam demais!”. O cansaço é a forma mais recorrente de descrever esses encontros, de acordo com os relatos que ouvi. A "falta de tempo" para descansar, cuidar de assuntos pessoais e ficar com a família faz com que deixem de ir às reuniões e questionem a eficácia desse método. O caráter rotineiro e "quase obrigatório" (COMERFORD, 2002, p. 150) desses encontros acentua a percepção de ineficácia. As reuniões são organizações distintas do cotidiano da comunidade que passaram a fazer parte da rotina como um efeito do desastre. No entanto, a intrusão dessa forma é tão avassaladora a ponto de controlar o tempo dos moradores.

De acordo com Luzia, o tempo corre "a favor das empresas", pois elas são capazes de gerir o tempo e submeter as (os) atingidas (os) a uma lógica burocrática, jurídica e administrativa com formas e linguagens próprias, dominadas pelos técnicos. As reuniões configuram espaços de conflitos, ao passo que configuram dispositivos capazes de neutralizar os embates com técnicas e burocracias, segundo a análise de Henri Acselrad (2018, p. 157) a respeito dessas questões do rompimento da barragem de Fundão. A Fundação Renova, controla o tempo e culpa os moradores pela demora dos processos por causa da quantidade de reuniões, por não negociarem direta e individualmente as indenizações e pelos impasses colocados pela assessoria técnica da Cáritas. Assim, a demora e o cansaço fazem com que alguns moradores negociem com as empresas e não participem do programa de reassentamento comunitário. Por outro lado, no caso das (os) 
atingidas (os) que se mobilizam e participam das reuniões e da Comissão, há a tentativa de agilizar as decisões e diminuir o número de reuniões, como também ficou evidente para a assessoria técnica que parou de fixar datas de "GTs", que ocorriam todas as sextas-feiras, depois que duas reuniões consecutivas foram canceladas devido à falta de participantes.

Em contrapartida, as (os) atingidas (os) criam maneiras de lidar com o tempo gerido pela Renova e a pressão que coloca aos moradores. Por mais que queiram resolver rapidamente suas condições de vida temporárias na cidade, os moradores não podem deixar de discutir os procedimentos nem reivindicar seus direitos com os responsáveis pela destruição da terra que habitavam. Nesse impasse, as atingidas e os atingidos criam métodos para organizar o tempo, como o exemplo que mostrarei na próxima seção.

\section{"Ir aos poucos"}

No meu primeiro encontro com Luzia, em outubro de 2018, recebi seu conselho de "ir aos poucos" e "chegar nas pessoas devagar": falar pouco, fazer meus próprios contatos e, ao mesmo tempo, mostrar que não sou vinculada à Fundação Renova nem à Samarco. Segui essa indicação como uma metodologia tanto em minha relação com os moradores, quanto na tentativa de desenvolver a pesquisa e escrever uma etnografia. No entanto, analisando as reuniões de que participei em janeiro e fevereiro de 2019, percebi que esse é, também, um método das (os) atingidas (os).

A destruição da terra natal, o deslocamento para zona urbana e a impossibilidade de desempenhar as atividades cotidianas, principalmente as atividades agrícolas, alteraram completamente as referências e as formas de contar o tempo entre os moradores. Dessa maneira, as (os) atingidas (os) precisaram criar estratégias para viver em um mundo totalmente outro, depois do "fim do nosso mundo", como mencionam. Assim, formularam métodos para lidar com a rotina extraordinária, marcada por um tempo incontrolável e incontornável.

"Ir aos poucos" é o oposto do que se impõe e do que se espera na rotina do extraordinário. Minha hipótese é que, de acordo com a lógica empresarial das mineradoras e da Fundação Renova, "ir aos poucos” seria como se deixar levar pela burocracia, perderse nos papéis e ignorar a passagem do tempo. A ideia "tempo é dinheiro" dita as ações de "indenização", "reassentamento", "reparação" e "compensação". Sabendo que o "tempo está a favor das mineradoras", as (os) atingidas (os) pensam o tempo a seu modo, tentando conter os movimentos das empresas, pensando e articulando seus próprios movimentos. 
Lembrando o questionamento de uma moradora mencionado no início da seção anterior: "Por que a gente vai chutar, se estamos caminhando esse tempo todo?!".

O interesse das (os) atingidas (os) não é ter uma casa nova nos termos da "compensação", mas, sim, não ter sua casa destruída, como deixou claro Zaia quando elogiei sua casa na cidade: "Não gosto daqui, não. Queria mesmo é minha casa em Paracatu". É evidente que preferiam viver na zona rural, sem depender das verduras da feira, dos ônibus para o deslocamento urbano, das reuniões e da Fundação Renova, mas o reassentamento e as indenizações não "reparam" a destruição provocada pelo desastre.

"Ir aos poucos" é uma forma de viver no extraordinário, sem se deixar levar, sem se deixar interromper e enlouquecer. Aproximo ao método proposto por Isabelle Stengers (2015, p. 45-47) ao falar em "hesitar" e "compor com Gaia", criando junto com todos os seres vivos, durante a extinção das espécies causada por um modelo de destruição em busca do lucro incessante, em máxima velocidade. Desse modo, "ir aos poucos" é hesitar, não "chutar", como disse a atingida. Para isso, é necessário assumir os riscos e identificar os problemas. Luzia mencionou no seminário "Mariana 3 Anos Depois", que a Renova determina como deve ser o reassentamento pensando no meio ambiente, limitando a Área de Proteção Permanente (APP), contrariando o fato de que "eles" destruíram a Bacia do Rio Doce e "nós já erámos ambientalistas", em referência às roças em Paracatu de Baixo.

Da mesma forma, os moradores se levantaram na reunião do dia 06 de novembro de 2018, com pesquisadores contratados pela Renova para avaliar a qualidade do solo, da água e do ar nas comunidades atingidas. Diante dos resultados "positivos", as (os) atingidas (os) expuseram seus casos, suas doenças respiratórias, estomacais e dérmicas. Os pesquisadores responderam que não poderiam afirmar a relação entre essas doenças e os rejeitos minerais despejados. Em seguida, Luzia anunciou: "vou fazer um banquete e mandar servir para todos da Renova, só com comida tirada de Paracatu, para ver se vocês têm coragem de comer".

Por outro lado, as mineradoras seguem um padrão de ação global, aderindo às críticas, falando em "desenvolvimento sustentável”, sem redução considerável dos danos às comunidades e ao meio ambiente, como analisa Stuart Kirsch (2014). As ações dessas empresas são muito semelhantes: abuso de direitos; controle das informações, negando, mentindo, omitindo dados e manipulando pesquisas; financiamento de projetos políticos que facilitam a alteração nas legislações ambientais e a produção de laudos favoráveis. A própria BHP Billiton, uma das proprietárias da barragem de Fundão, foi responsável por 
um dos maiores desastres ambientais do mundo, com o despejo de minério no rio $\mathrm{Ok}$ Tedi, na Papua Nova Guiné (KIRSCH, 2006).

"Ir aos poucos" não é traduzido na lógica das mineradoras, formada por máquinas, tabelas, projeções e cálculos. As empresas calculam os riscos e determinam o que será menos custoso, como no caso da geração de energia classificada como um "mal necessário", como mostrou Catarina Morawska Vianna (2014) a respeito da Usina de Belo Monte. Em Mariana essa situação continua após o desastre, como mostra a ação das mineradoras em construir diques de contenção alagando os terrenos de famílias já atingidas em Bento Rodrigues, sem o consentimento dos moradores que tiveram seus terrenos tomados. Nesse jogo, o papel das (os) atingidas (os) se limita a um acordo em forma de indenização ou a espera pelo reassentamento, seja esse "familiar" ou "coletivo", isto é, separado ou junto à comunidade, em terrenos escolhidos dentre as opções apresentadas pela Renova.

Uma estratégia elaborada pelos moradores de Paracatu de Baixo, seguindo o método que criaram, é construir casas em áreas de "ocupação" com parte do valor da indenização. Assim, com um terreno próprio, podem construir casas que atendam às suas necessidades, diferentemente daquelas alugadas pela Renova. A esse respeito, uma moradora me contou da visita de uma representante da Renova à sua casa, reclamando da dificuldade em chegar às "áreas irregulares" pelos morros e ruas não asfaltadas, questionando: "Agora que vocês têm essa casa, vão querer, ainda, a casa no reassentamento?". A atingida afirmou que respondeu enfurecida, pois era "um direito" dela e que queria "morar em Paracatu", sendo que tudo o que fizeram foi porque precisaram e, vão, sim, ter as duas casas. Nesse sentido, à medida que as empresas tentam "desqualificar o conjunto do habitat planetário, despojando os povos de sua qualidade de habitante", nos termos de Gilles Deleuze e Félix Guattari (1997, p. 169), em uma nota a respeito de Paul Virilio, as (os) atingidas (os) seguem fazendo casas e quintais quando possível, desviando-se da lógica binária, coercitiva e veloz de produção capitalista.

Por fim, é possível ver esse método numa estratégia que adere a maioria dos moradores, convergindo a comunidade: os rituais católicos. Como mencionei anteriormente, a Igreja de Santo Antônio é o único prédio que não foi totalmente destruído nas proximidades do rio Gualaxo do Norte. Desde o deslocamento compulsório, os moradores lutam para poder realizar as festas do Padroeiro Santo Antônio, em junho, do Menino Jesus, em setembro, a celebração de Nossa Senhora Aparecida, em outubro e a Folia de Reis, marcando o fim e o início do ano. Dessa forma, eles reivindicam a terra e a 
ocupam, mesmo contra as indicações da Fundação Renova, que controlou o acesso dos moradores ao local até o início de 2018. A luta dos moradores seguiu com o auxílio da Arquidiocese de Mariana até conseguirem a liberação da Defesa Civil para o uso da Igreja.

O método de "ir aos poucos" contém a velocidade do tempo. "Ir aos poucos" equivale a uma maneira de se portar, de agir e de se relacionar com o tempo. Os moradores são "atingidos todos os dias" ao sentir o tempo com rapidez e escassez, devido à rotina extraordinária que lhes foi imposta. Do mesmo modo que precisaram "aprender a ser atingido" e "aprende a linguagem", eles precisaram "aprender" a "ir aos poucos". Essas formulações indicam metodologias de "luta" que os moradores criaram ao se posicionarem diante das devastações impunes causadas pelas mineradoras.

\section{Considerações finais}

As condições que acompanhei durante minha primeira experiência de pesquisa com a comunidade de Paracatu de Baixo foram cercadas de tensões e dificuldades. Contudo, a partir delas pude perceber que o cotidiano da comunidade foi impedido de se manifestar após o rompimento da barragem de Fundão. Nesse sentido, utilizei as duas figuras de linguagem para enfatizar o problema que me deparei: o pleonasmo, cotidiano ordinário, remete ao passado na zona rural, marcado pelas relações de vizinhança, pelo trabalho na roça, pela brincadeira no rio Gualaxo do Norte e pelos encontros nas missas, celebrações e festas na Igreja de Santo Antônio; e o oximoro, rotina extraordinária salienta as diferenças do tempo na zona urbana, dissociado da terra natal e dos modos de vida, onde os moradores vivem distantes de seus vizinhos, sem suas hortas e seus animais criados nos pastos. Esses dois modelos são evidentes nas falas das atingidas e dos atingidos, que comparam as formas de vida, considerando o rompimento da barragem de rejeitos um marco temporal.

As perdas e o sofrimento são sentidos diariamente, faltam-lhes os quintais e as hortas, os parentes que eram vizinhos, muitos com casas no mesmo terreno; a criação de porcos e galinhas; a cachoeira do rio Gualaxo do Norte; as grandes festas na Igreja. Sem esses marcadores temporais que guiavam a vida cotidiana em Paracatu de Baixo não se estabelece os modos de vida da comunidade. Mais do que isso, a organização técnica, jurídica e burocrática, que surge como um efeito do desastre, impede a retomada do cotidiano, marcado por um novo modelo, incerto e inseguro, dominado pelas mineradoras criminosas. 
Os moradores se organizam em um contexto temporário, que se estende por quase cinco anos. Essa espera contínua dificulta a construção de planos, o arranjo de novas ocupações e a construção de novas relações. O sofrimento resultante das perdas, dos impedimentos e da destruição aumenta no mesmo ritmo em que seus direitos são negados, em processos longos cuja outra parte é composta pelas maiores companhias de mineração do mundo. Contudo, a existência das (os) atingidas (os) implica a luta, seja nos meios técnicos e jurídicos, com o auxílio da Cáritas Brasileira e do Ministério Público, seja criando estratégias próprias da comunidade, que não se restringem aos saberes técnicos. Essas estratégias mostram-se como uma potência para os moradores, a exemplo das técnicas de "ir aos poucos": discutindo e conversando nas reuniões, mas também construindo casas e buscando a terra natal como referência para o reassentamento, sem deixar de reivindicá-la como lugar da comunidade, evidente nos rituais católicos feitos na Igreja em meio à "lama".

As dificuldades em habitar um mundo destruído entram em minhas dificuldades de pesquisa, que não podia acompanhar o ritmo dos "atingidos todos os dias". Tentei seguir o método de minhas interlocutoras, caminhando devagar e aos poucos, sem "chutar". Assim, as atingidas e os atingidos concentram-se na comunidade e vão aos poucos, evitando a força do extraordinário representada pela Fundação Renova, responsável por administrar o tempo, ora barrando os processos jurídicos, cancelando reuniões e perpetuando as análises reivindicadas pelos moradores, ora soltando seu fluxo avassalador, passando por cima de todos os seres, pressionando decisões e negociando indenizações.

\section{Notas:}

1. Este artigo é decorrente de minha pesquisa de Iniciação Científica financiada pela Fundação de Amparo à Pesquisa do Estado de São Paulo (FAPESP), processo no. 2018/07693-5, cujos resultados estão em minha monografia de conclusão de curso em Ciências Sociais na Universidade Federal de São Carlos. Agradeço à Fapesp pelo financiamento atual de minha pesquisa, processo nº. 2019/27182-8. Agradeço à comunidade de Paracatu de Baixo, especialmente à Luzia por corrigir meu texto. Agradeço ao Prof. Dr. Jorge Villela por orientar meu trabalho. Por fim, agradeço às/aos pareceristas pelos comentários que me auxiliaram nesta última versão.

2. As palavras em itálico são termos utilizados pelos moradores de Paracatu de Baixo, fundamentais para minha análise. Entre aspas estão as falas e expressões que ouvi na pesquisa de campo e as citações bibliográficas, sempre referenciadas. 
3. No município de Mariana, oito comunidades rurais foram atingidas pela "lama": Bento Rodrigues, Camargos, Bicas, Ponte do Gama, Paracatu de Cima, Paracatu de Baixo, Pedras e Campinas.

\section{Referências:}

ACSELRAD, Henri. Mariana, novembro de 2015: a genealogia política de um desastre. In: ZHOURI, Andréa (org.). Mineração, violências e resistências. Marabá: Editorial iGuana, ABA, 2018, pp. 155-174

BROWN, Hannah; REED, Adam; YARROW, Thomas. Introduction: towards an ethnography of meeting. Journal of the Royal Anthropological Institute, v. 23, n. S1, p. 10-26, 2017.

CALIS, Juan; FULLER, Claudia; LAGOS, Vanesa; DÍAZ CROVETTO, Gonzalo. Riesgo, Territorio e Instituciones en la Antropología de las Catástrofes. Aportes a una perspectiva en construcción. Papeles de Trabajo, Centro de Estudios Interdisciplinarios en Etnolingüística y Antropología Socio-Cultural, n. 34, dic. 2017.

COMERFORD, John Cunha. Reuniões camponesas, sociabilidade e lutas simbólicas. In: PEIRANO, Mariza (org.). O dito e o feito: ensaios de antropologia dos rituais. Rio de Janeiro: Relume Dumará, Núcleo de Antropologia da Política/UFRJ, 2002, pp. 149-169.

. Como uma família: sociabilidade, territórios de parentesco e sindicalismo rural. Rio de Janeiro: Relume Dumará, Núcleo de Antropologia da Política/UFRJ, 2003.

DAS, Veena. Critical Events: An Anthropological Perspective on Contemporary India. USA: Oxford University Press, 1995.

DAWSEY, John Cowart. "Caindo na cana" com Marilyn Monroe: tempo, espaço e "bóias-frias". Revista de Antropologia, USP, v. 40, n. 1, 1997.

DELEUZE, Gilles; GUATTARI, Félix. Proposição XIV: Axiomática e Situação Atual. Mil Platôs - 5. São Paulo: Ed. 34, 1997, pp. 161-177.

FAVRET-SAADA, Jeanne. "Ser afetado". SIQUEIRA, Paula (trad.). Cadernos de Campo, n. 13, pp. 155-161, 2005

GOLDMAN, Marcio. "Jeanne Favret-Saada, os afetos e a etnografia". Cadernos de Campo, n. 13, pp. 149-153, 2005.

KIRSCH, Stuart. Reverse Anthropology: Indigenous Analysis of Social and Environmental Relations in New Guinea. Stanford, CA: Stanford University Press, 2006. Mining capitalism: The relationship between Corporations and their critics. Oakland: University of California Press, 2014. 

2019.

KRENAK, Ailton. Ideias para adiar o fim do mundo. São Paulo: Companhia das Letras,

MANTOVANELLI, Thais. Os Xikerin de Bacajá e a Usina Hidrelétrica de Belo Monte: uma crítica indígena à política dos brancos. 2016. 258 f. Tese (Doutorado em Antropologia Social) - Programa de Pós-Graduação em Antropologia Social, Universidade Federal de São Carlos, São Carlos, 2016.

MILANEZ, Bruno; LOSEKANN, Cristiana (orgs.). Desastre no V ale do Rio Doce: antecedentes, impactos e ações sobre a destruição. Rio de Janeiro: Folio Digital: Letra e Imagem, 2016.

MORAWSKA VIANNA, Catarina. A trilha de papéis da usina hidrelétrica de Belo Monte: tecnologias de cálculo e a obliteração da perspectiva dos povos impactados. Revista Anthropologicas, ano 18, v. 25, n. 2, pp. 22-40, 2014.

OLIVER-SMITH, Anthony. "What is a disaster?": Anthropological perspectives on a persistent question. In: New York: Routledge, 1999. ; HOFFMAN, Susanna F. (Ed.) The Angry Earth.

PALMEIRA, Moacir. Feira e mudança econômica. Vibrant, v. 11, n. 1, 2013 [1971].

PEIRANO, Mariza. Prefácio; A análise antropológica de rituais. In.: (org.) $O$ dito e o feito: ensaios de antropologia dos rituais. Rio de Janeiro: Relume Dumará, Núcleo da Antropologia da Política, UFRJ, 2002, pp. 7-41.

RILES, Annelise. Outputs: the promises and perils of ethnographic engagement after the loss of feith in transnational dialogue. In: Special Issue: Meetings: ethnographies of organizational process, bureaucracy, and assembly. Journal of the Royal Anthropological Institute, v. 23, n. S1, p. 1026, 2017.

STENGERS, Isabelle. No tempo das catástrofes: resistir à barbárie que se aproxima. São Paulo: Cosac Naify, 2015. 2014.

STRATHERN, Marilyn. O efeito etnográfico e outros ensaios. São Paulo: Cosac \& Naify,

SWORD-DANIELS, Victoria; ERIKSEN, Christine; HUDSON-DOYLE, Emma E.; ALANIZ, Ryan; ADLER, Carolina; SCHENK, Todd Schenk; VALLANCE, Suzanne. Embodied uncertainty: living with complexity and natural hazards. Journal of Risk Research, Estados Unidos, 2016. Disponível em: http://dx.doi.org/10.1080/13669877.2016.1200659. Acesso em: 10 dez. 2018.

TADDEI, Renzo. O lugar do saber local (sobre ambiente e desastres). In: Riscos de desastres relacionados à água. São Carlos: RiMa Editora, pp. 311-325, 2015.

TAMBIAH, Stanley Jeyaraja. Culture, Thought, and Social Action. An Anthropological Perspective. Cambridge, Mass.: Harvard University Press, 1985.

WOORTMANN, Ellen F. Da complementaridade à dependência: espaço, tempo e 
gênero em comunidades "pesqueiras" do Nordeste. Revista Brasileira de Ciências Sociais, n. 18, ano 7, pp. 41-61, 1991.

ZHOURI, Andréa. Introdução. In: (org.). Mineração, violências e resistências: um campo aberto a produção de conhecimento no Brasil. $1^{a}$ ed., Marabá: Editorial iGuana; ABA, 2018.

Recebido em 16 de dezembro de 2019 Aceito em 12 de maio de 2020 